\title{
Unchanged prevalence of shell disease in the edible crab Cancer pagurus four years after decommissioning of a sewage outfall at Langland Bay, UK
}

\author{
Adam Powell, Andrew F. Rowley* \\ Department of Biological Sciences \& Institute of Environmental Sustainability, University of Wales Swansea, Singleton Park, \\ Swansea SA2 8PP, UK
}

\begin{abstract}
Shell disease is a bacteria-associated degradative disease of the crustacean exoskeleton that leads to formation of extensive lesions in the cuticle with ultimate involvement of haemocoelic septicaemia. Field surveys of edible crabs Cancer pagurus from Langland Bay, Gower, UK, from February 1997 to March 1998 had revealed unusually high prevalence (ca. 55\%) of this disease amongst the population, and it was suggested that one of the predisposing factors might have been the presence of raw sewage in this area. Since February 1999, a local raw sewage outfall affecting this area has been decommissioned, raising the possibility that the prevalence and severity of this disease could have become reduced as a result of the cessation of sewage exposure. Therefore, the aim of this study was to compare the prevalence and severity of shell disease in edible crabs from Langland Bay pre- and post-sewage discharge. The overall prevalence of shell disease from February 2003 to March 2004 was $59.2 \%$, and in only 1 size class (80-99 mm carapace width, males) was the prevalence higher in 2003-04 than in 1997-98. In terms of severity, only smaller crabs (60-199 mm width) showed a significant reduction in 2003-04 compared with 1997-98. No changes were found in the severity of the disease in different regions of the exoskeleton of infected crabs between the 1997-98 survey and the present work. Overall, it is concluded that no significant changes in the occurrence of shell disease have resulted from the improvement in water quality (in terms of faecal pollution) at this site, suggesting that sewage pollution is probably not a major contributory factor to this disease.
\end{abstract}

KEY WORDS: Shell disease $\cdot$ Cancer pagurus $\cdot$ Crustacea $\cdot$ Pollution

Resale or republication not permitted without written consent of the publisher

\section{INTRODUCTION}

Shell disease is a global phenomenon that affects many marine crustaceans (Getchell 1989), including the edible crab Cancer pagurus. In this disease, bacteria including various Cytophaga-Flavobacter species, vibrios, pseudomonads and Pseudoalteromonas spp. (Vogan et al. 2002, Ziino et al. 2002, Becker et al. 2004, Costa-Ramos \& Rowley 2004) collectively degrade the exoskeleton using chitinases and other enzymes, and initiate a host-derived melanisation response in the carapace. Ultimately the crab may die either from septicaemia (if the damaged cuticle is breached and these or other bacteria gain entry to the open haemocoele: Vogan et al. 2001) or from an inability of such individuals to withdraw from the shell at ecdysis (Fisher et al. 1978).

Vogan et al. (1999) showed an unusually high prevalence (ca. $55 \%$ ) of shell disease in Cancer pagurus populations in Langland Bay near Swansea sampled in 1997-98. Further west along the Gower Peninsula, at Rhossili, levels of disease were significantly less 
(Vogan \& Rowley 2002). These latter authors suggested that this difference could be linked to a number of environmental factors, particularly those associated with raw sewage discharge near Langland. Similarly, other workers have suggested that shell disease levels may be correlated with pollution (e.g. Gopalan \& Young 1975, Young \& Pearce 1975, Shields 2003). Young \& Pearce (1975) found that rock crabs C. irroratus and lobsters Homarus americanus maintained in aquaria containing sewage sludge and dredge spoils from the New York Bight developed cuticular lesions similar to those found in shell disease affected individuals from the wild. In the Albermarle-Pamlico Estuary, Noga et al. (1994) reported that low serum antibacterial activity correlated with increased prevalence of shell disease in blue crabs Callinectes sapidus. It was suggested by these authors that a reduction in environmental quality could result in immune suppression which, in turn, could result in enhanced bacterial growth in the cuticular lesions. In general, although there is some indication of a link between environmental quality and shell disease, the limited data are equivocal.

Since the 1997-98 survey on shell disease prevalence and severity in Cancer pagurus (Vogan et al. 1999), the raw sewage outfall near to Langland Bay has been decommissioned. Between May 1998 and February 1999 it was $50 \%$ operational until its total closure in February 1999. As the occurrence of this disease has previously been implicated with sewage sludge dumping (Gopalan \& Young 1975), the prevalence and severity of the disease in Langland Bay would be expected to have declined in the meantime due to the cessation of sewage pollution. Therefore, this study compared the prevalence and severity of shell disease in edible crabs from Langland Bay pre- and postsewage treatment operationals. The timing of this survey provided a unique opportunity to test the hypothesis that sewage pollution is one of the factors that influences the prevalence and severity of shell disease in a natural environment.

\section{MATERIALS AND METHODS}

A year-long monthly shore survey for Cancer pagurus commenced in February 2003 at Langland Bay on the Gower Peninsula of South Wales, UK. Sampling methodology and data recording were performed using the same protocols as employed by Vogan et al. (1999) in their survey of shell disease at this same site. This enabled direct comparison between data collected from February 1997 to March 1998 reported in Vogan et al. (1999) and February 2003 to March 2004 (current study). Briefly, all crabs collected from the survey site at Langland (see Fig. 1) were sexed, their carapace widths measured and the size and position of shell disease lesions on the surfaces recorded. Shell disease prevalence was defined as the proportion of crabs with 1 or more lesions at the time of collection, while severity was defined as the percentage of exoskeleton (dorsal and ventral surfaces) in affected crabs covered by lesions. The size and location of lesions were recorded on site onto a standard outline of C. pagurus adapted from Warner (1977), thus enabling an estimate of the percentage of exoskeleton covered by lesions to be determined. For consistency with the previous 1997-98 study, ecdysed crabs at moult Stages A and B were excluded. Male and female disease prevalence data were analysed using contingency tables combined with Fisher's exact test (between years) or chi-squared test (2003-04 data). Disease severity data between years were analysed using Student's $t$-test against equal size classes, with male and female data grouped together for clarity. Severity data are shown as mean values \pm SE (see Fig. 4).

\section{RESULTS AND DISCUSSION}

Since 1999, sewage from Swansea has been UV treated and the effluent discharged into eastern Swansea Bay ca. $7 \mathrm{~km}$ away from the survey site (Fig. 1). The original raw sewage discharge site close to Langland Bay was decommissioned, with total closure in February 1999. Environment Agency (UK) data (see www.environment-agency.gov.uk) has shown a large reduction in total coliform counts for Langland Bay since the original 1997-98 survey of Vogan et al. (1999) (Fig. 2). Similarly, the number of faecal coliforms and faecal streptococci also declined since 1998 (data not shown). Sewage may potentially elevate the abundance, diversity and growth kinetics of chitinolytic bacteria in the sediment, thereby increasing the chance of infection. For example, large bacterial

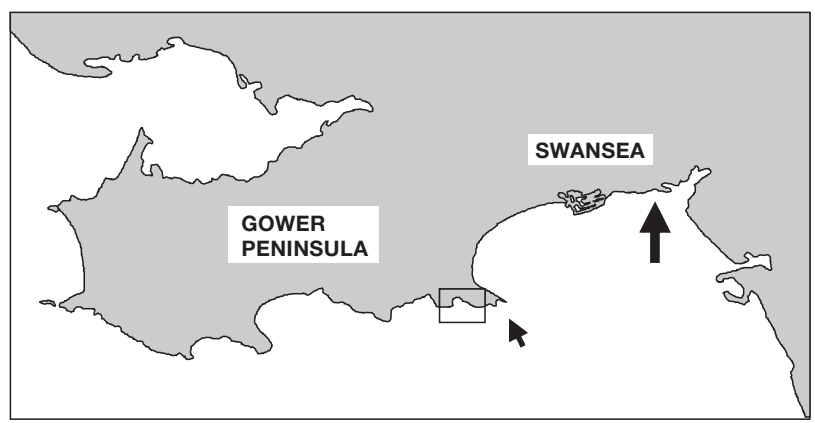

Fig. 1. Gower Peninsula, South Wales, UK, showing survey site of Langland Bay (boxed area) in relation to old (small arrow) and new (large arrow) sewage discharge sites. (Modified from Vogan et al. 1999) 


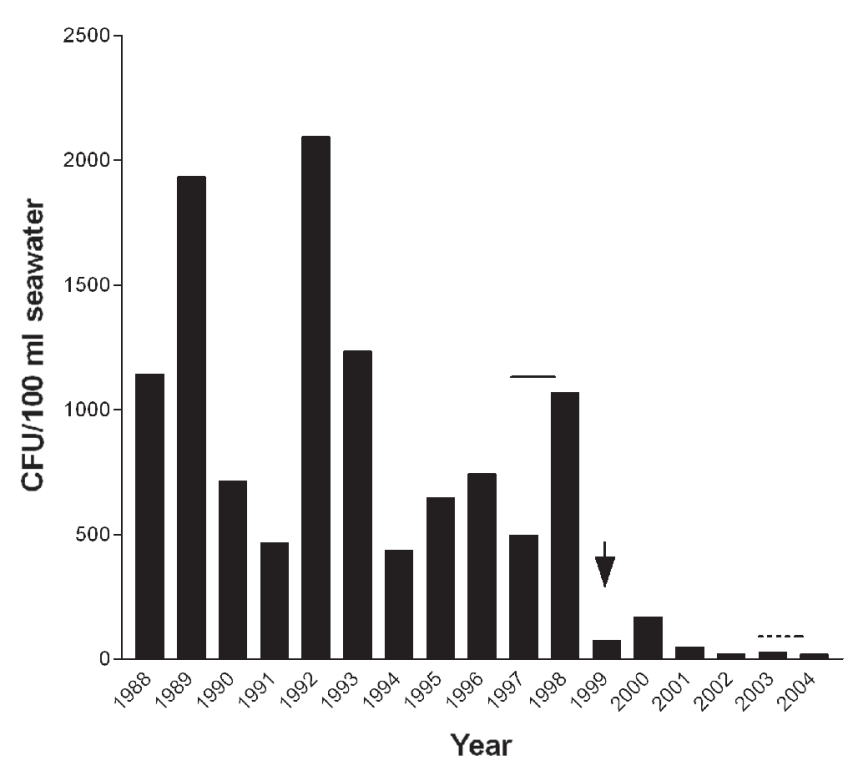

Fig. 2. Mean coliform counts for Langland Bay for period 1988 to 2004 during bathing season (May to September). Continuous line: 1997-98 shell disease survey period; dotted line: current 2003-04 survey period; arrow: point at which sewage outfall near Langland Bay was decommissioned. (Data from Environment Agency UK: www.environment-agency.gov.uk)

abundances have been widely reported in sediments with high organic content (e.g. Yamamoto \& Lopez 1985, Sander \& Kalff 1993). However, no data exist to suggest that the bacteria associated with shell disease lesions exist in human faeces in significant numbers (Vogan et al. 2002, Becker et al. 2004). Hence, the potential causative agents of shell disease are unlikely to be harboured in human sewage in any significant numbers.

The mean prevalence of shell disease in 2003-04 was $59.2 \%$ compared with $55.4 \%$ in $1997-98$. In the 1997-98 data, significantly more males than females sampled had shell disease lesions (63.1 vs. $40.1 \%$ respectively; Vogan et al. 1999). In 2003-04,63.0\% of the males had 1 or more lesions compared with $50.8 \%$ of the females ( $p>0.05$; male vs. female). Shell disease prevalence between the sampling years was generally not significantly different for the same sex size classes, with only the 80-99 mm male size class having significantly more disease in 2003 than in 1997 (Fisher's exact test, p < 0.05) (Fig. 3). In the case of female crabs, the apparent increase between 1997-1998 and 2003-2004 in prevalence of the disease in the $>140$ mm size class (see Fig. 3B) arose from the small sample size (it was difficult to collect crabs of this size range as this is the legal limit for commercial collection).

In 2003-04, as in 1997-98, disease severity increased with increasing carapace size, with the greatest severity occurring in the 120 to $139 \mathrm{~mm}$ size class
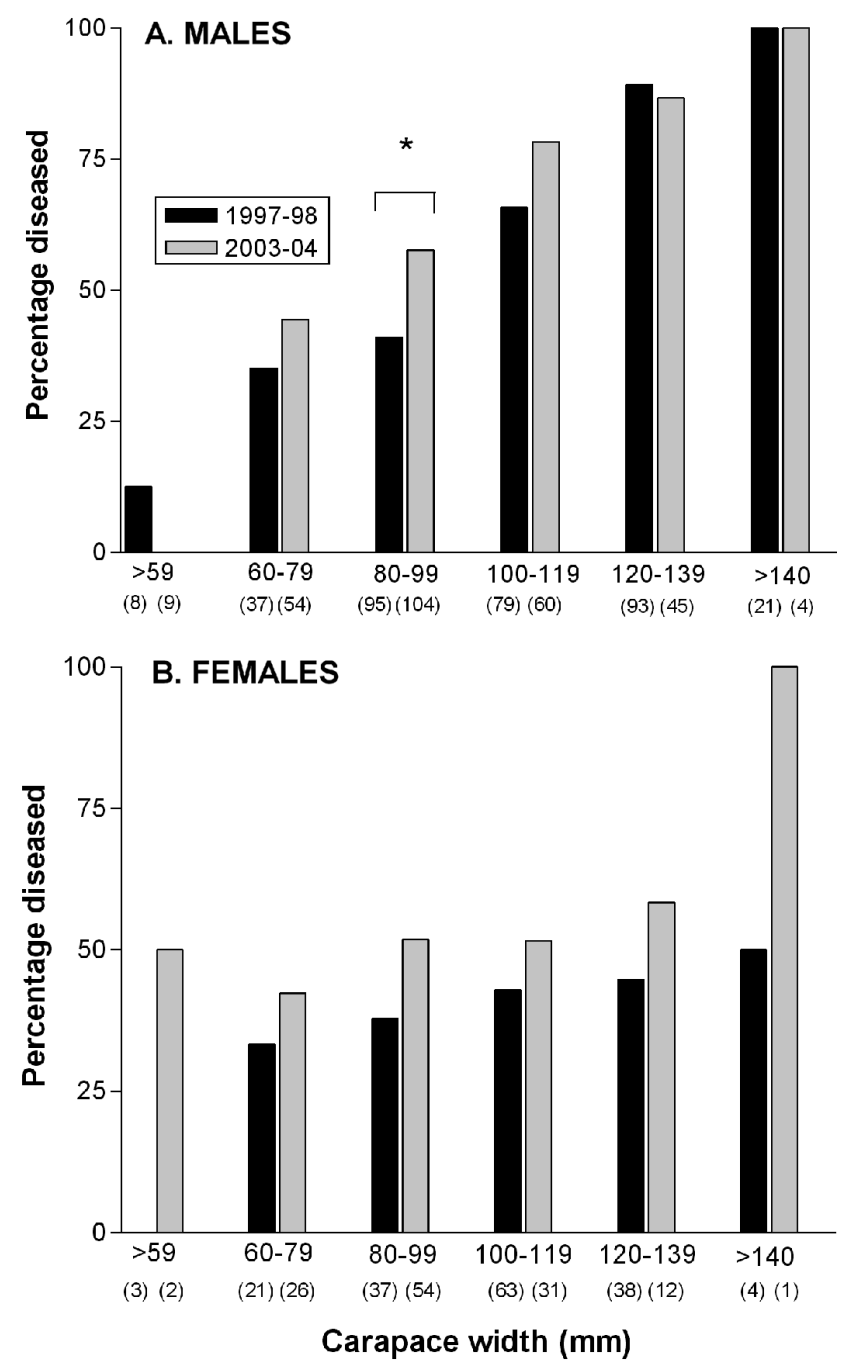

Fig. 3. Cancer pagurus. Prevalence of shell disease lesion occurrence within each size class for 1997-98 and 2003-04 for male and female crabs. Smallest $(<59 \mathrm{~mm})$ and largest (>140 mm) size classes were not statistically tested because of small sample sizes in 2003-04 ( $\mathrm{n}=1$ to 9 ). * Significantly different (Fisher's exact test, $\mathrm{p}<0.05$ ) from size class $80-99 \mathrm{~mm}$. Sample sizes in parentheses

$(0.81 \pm 0.16 \%$ of body covered by lesions; $\mathrm{n}=46)$. However, 3 size classes had significantly less disease severity in 2003 than 1997; the 60-79 $\mathrm{mm}$ size class (Student's $t$-test, $\mathrm{p}<0.01$ ), and the 80-99 and 100-119 mm size classes (Student's $t$-test, $\mathrm{p}<0.05$ ) (Fig. 4). Although the larger size classes apparently showed a reduction in severity between 1997-98 and 2003-04, this arose from the small sample size of the $>140 \mathrm{~mm}$ group and the large amount of variation in individual data.

Similar trends were found in the distribution of lesions in shell disease affected crabs between the original survey in 1997-98 and the current 2003-04 


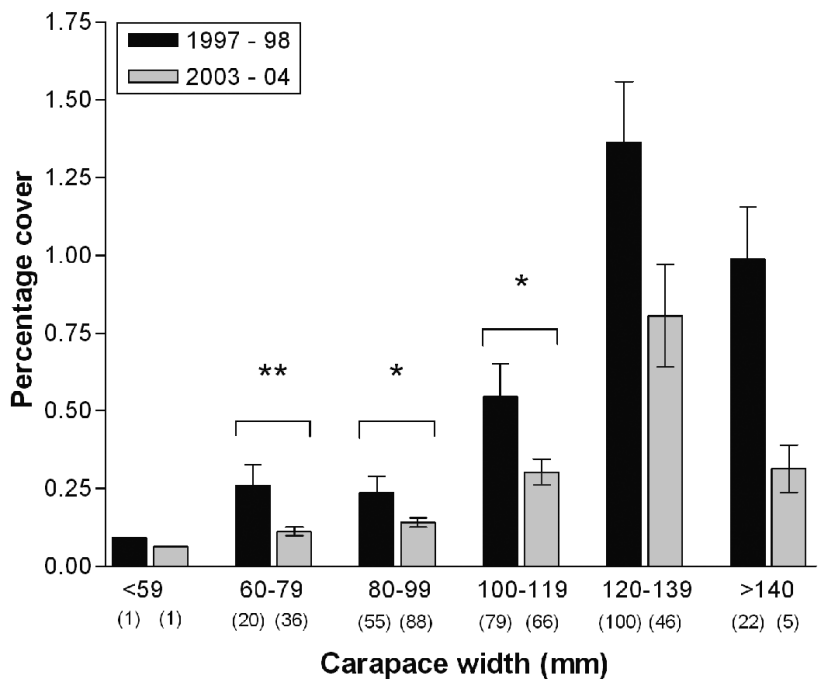

Fig. 4. Cancer pagurus. Severity of shell disease expressed as mean percentage $( \pm \mathrm{SE})$ of exoskeletal surface covered by lesions amongst diseased individuals from each size class for 1997-98 and 2003-04; $<59 \mathrm{~mm}$ size classes not tested statistically because of small sample sizes. *Significantly different (Student's $t$-test, $\mathrm{p}<0.05$ ) from size class 80-99 and 100-119 mm, ${ }^{* *}$ significantly different (Student's $t$-test, $\mathrm{p}<$ 0.01) from size class $60-79 \mathrm{~mm}$. Sample sizes in parentheses

study (Fig. 5). As in the 1997-98 survey, the dorsal carapace of both male and female crabs was the most commonly affected area. The distribution of lesion occurrence on the different regions of the crabs' dorsal exoskeleton did not differ significantly between males sampled in 1997-98 and in 2003-04, while in female crabs, the prevalence was higher in 2003-04 than in 1997-98 (Fisher's exact test, $\mathrm{p}<0.001$ ). Where differences existed between male and females in terms of prevalence of lesion occurrence, such as in the chelae and periopods, similar trends were also apparent in the 2003-04 data; however, the percentage prevalence was significantly lower in 2003-04 in the periopods of males than in equivalent individuals in 1997-98 (Fisher's exact test, $\mathrm{p}<0.01$ ).

Although the current study has failed to show any major changes in the prevalence of shell disease at Langland Bay since the original 1997-98 survey of Vogan et al. (1999), smaller sized crabs collected in 2003-04 did show a significant reduction in disease severity. It could be argued that this may be related to sewage as young crabs would not have been exposed to such pollutants of the late 1990s. Overall, however, despite the dramatic improvement in faecal pollution in Langland Bay, shell disease remains a significant problem affecting these commercially important crabs. Our data fail to support the hypothesis that faecal pollution influences the prevalence of shell disease. However, the potential microbial enrichment in the sedi-

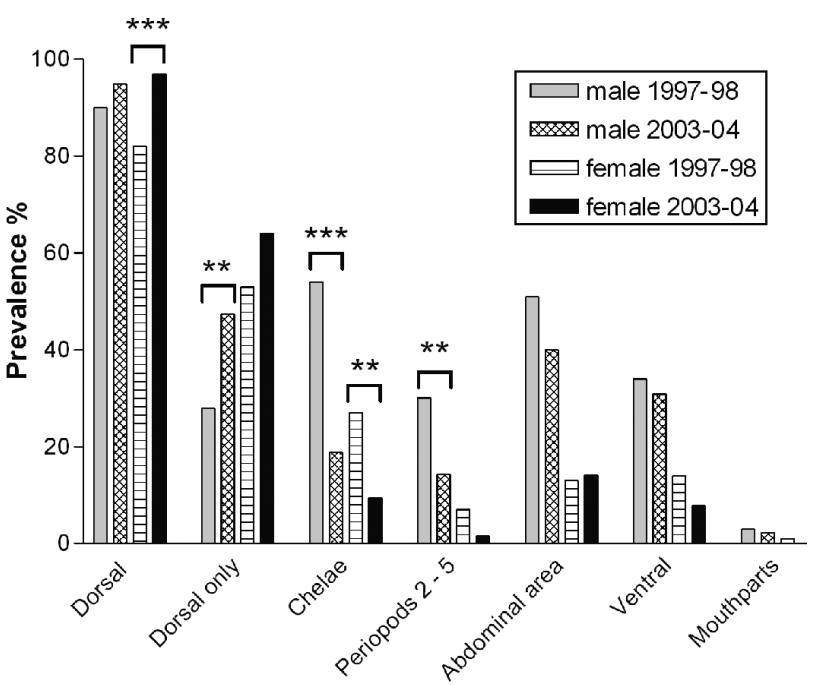

Fig. 5. Cancer pagurus. Prevalence of lesion occurrence on various regions of shell disease affected male and female crabs surveyed in 1997-98 and 2003-04. (Data for 1997-98 are from Vogan et al. 1999.) ${ }^{* *},{ }^{* * *}$ Significantly different at $\mathrm{p}<0.01$ and $\mathrm{p}<0.001$ respectively (Fisher's exact test)

ment resulting from sewage pollution may have a longer lasting effect than reflected in the coliform counts in water shown in Fig. 2. It is therefore of importance to maintain this survey over the next decade to reveal longer term changes, if any. Why this site has such an unusually high prevalence of shell disease is unclear. Our lack of knowledge of the microbial populations associated with shell disease hampers further progress, and in particular the potential role of xenobiotics and external stressors in direct or indirect regulation of such populations needs exploring. In this respect, the recent elucidation of bacterial populations using 16s rDNA sequencing from the lesions of shell disease affected lobsters Homarus americanus from a wide range of sites off the eastern seaboard of North America (Becker et al. 2004) may enable researchers to answer these key questions in the near future.

Acknowledgements. We thank Dr. Claire Vogan for the provision of the original shell disease data (1997-98) and for helpful discussions. A.P. was supported by a University of Wales Swansea studentship bursary.

\section{LITERATURE CITED}

Becker P, Smolowitz R, Porter M, Hsu A, Roberts S (2004) Characterization of bacteria associated with lobster shell disease. Biol Bull (Woods Hole) 207:171

Costa-Ramos C, Rowley AF (2004) Effect of extracellular products of Pseudoalteromonas atlantica on the edible crab, Cancer pagurus. Appl Environ Microbiol 70:729-735

Fisher WS, Nilson EH, Steenbergen JF, Lighter DV (1978) 
Microbial diseases of cultured lobsters: a review. Aquaculture 14:115-140

Getchell RG (1989) Bacterial shell disease in crustaceans: a review. J Shellfish Res 8:1-6

Gopalan UK, Young JS (1975) Incidence of shell disease in shrimp in the New York Bight. Mar Pollut Bull 6:149-153

Noga EJ, Engel DP, Arroll TW, McKenna S, Davidian M (1994) Low serum antibacterial activity with increased prevalence of shell disease in blue crabs, Callinectes sapidus. Dis Aquat Org 19:121-128

Sander BC, Kalff J (1993) Factors controlling bacterial production in marine and freshwater sediments. Microb Ecol 26:79-99

Shields JD (2003) Research priorities for diseases of the blue crab Callinectes sapidus. Bull Mar Sci 73:505-517

Vogan CL, Rowley AF (2002) Dynamics of shell disease in the edible crab Cancer pagurus: a comparative study between two sites on the Gower Peninsula, South Wales, UK. Dis Aquat Org 52:151-157

Vogan CL, Llewellyn PJ, Rowley AF (1999) Epidemiology and

Editorial responsibility: Timothy Flegel,

Bangkok, Thailand dynamics of shell disease in the edible crab Cancer pagurus: a preliminary study of Langland Bay, Swansea, UK. Dis Aquat Org 35:81-87

Vogan CL, Costa-Ramos C, Rowley AF (2001) A histological study of shell disease syndrome in the edible crab Cancer pagurus. Dis Aquat Org 47:209-217

Vogan CL, Costa-Ramos C, Rowley AF (2002) Shell disease syndrome in the edible crab, Cancer pagurus-isolation, characterization and pathogenicity of chitinolytic bacteria. Microbiology (Reading) 148:743-754

Warner GF (1977) The biology of crabs. Elek Science, London Yamamoto N, Lopez G (1985) Bacterial abundance in relation to surface area and organic content of marine sediments. J Exp Mar Biol Ecol 90:209-220

Young JS, Pearce JB (1975) Shell disease from crabs and lobsters from the New York Bight. Mar Pollut Biol 6:101-105

Ziino G, Giuffrida A, Stancanelli A, Panebianco A (2002) Shell disease in Nephrops norvegicus from the Mediterranean sea. Morphological and hygienic remarks. Arch Lebensmittelhyg 53:134-136

Submitted: March 24, 2005; Accepted: September 27, 2005 Proofs received from author(s): December 27, 2005 